\title{
Avaliação de índices de conforto térmico de instalações para poedeiras no nordeste do Brasil ${ }^{1}$
}

\author{
Iánglio M. T. D. Jácome ${ }^{2}$, Dermeval A. Furtado ${ }^{3}$, Antonio F. Leal ${ }^{3}$, José H. V. Silva ${ }^{4}$ \& José F. P. Moura ${ }^{5}$
}

\begin{abstract}
RESUMO
Neste trabalho foram analisados os índices de conforto térmico de poedeiras na fase de cria e recria, em galpões cobertos com diferentes tipos de materiais de cobertura, instalados no Nordeste do Brasil. Todos os galpões foram avaliados através do índice de temperatura do globo negro e umidade (ITGU), da carga térmica de radiação (CTR) e da umidade relativa do ar (UR). A análise das médias mostrou que o ambiente construído proporcionou índices ambientais desconfortáveis tanto na fase de cria, onde os índices ficaram abaixo da zona de conforto, como na fase final, quando os índices ficaram acima da zona de conforto. Nos horários mais quentes do dia o galpão com cobertura de telhas cerâmicas apresentou melhor resultado na CTR, em comparação com o galpão com cobertura de telha de cimento amianto, proporcionando melhor conforto térmico para poedeiras na fase de recria.
\end{abstract}

Palavras-chave: qualidade dos ovos, postura, ambiência

\section{Evaluation of thermal comfort indexes for laying-hen houses in the Northeast of Brazil}

\begin{abstract}
In this study the thermal comfort indexes were analyzed in the growth phase of laying hens housed in installation with different types of roofing materials in the Northeast of Brazil. The laying hen-houses were assessed through black globe temperature and humidity index (WBGT), radiating thermal load (RTL) and the relative humidity. The mean analysis had showed that the laying-hen houses provided uncomfortable environmental indexes in all growth phases, where the thermal comfort indexes were below the thermal comfort zone during the early begining of chicken growing as well as in final phase when the indices were above the zone. During the hottest hours of the day, the laying-hen houses under ceramic roof tiles showed results in RTL better than the laying-hen houses using asbestos roofing tiles, providing best thermal comfort for laying hens in the growth phase.
\end{abstract}

Key words: eggs quality, layers, environment

\footnotetext{
1 Parte da Dissertação de Mestrado apresentada pelo primeiro autor ao Curso de Pós-Graduação em Engenharia Agrícola da UFCG, Campina Grande, PB

2 UAEAg/UFCG. Campina Grande, PB. CEP 58109-180. Fone: (19) 8127-5054. E-mail: ianglio@oi.com.br

3 UAEAg/UFCG. Campina Grande, PB. CEP 58109-180. Fone: (83) 3310-1486. E-mail: dermeval@deag.ufcg.edu.br

${ }^{4}$ DAP/UFPB. CEP 58.220.000, Bananeiras, PB. Fone: (83) 3367-1200. E-mail: jvilar@cft.ufpb.br

${ }^{5}$ Doutorando, CCA/UFPB. Areia, PB, CEP 58397-000. Fone: (83) 3362-2300. E-mail: jfpmoura@cca.ufpb.br
} 


\section{INTRODUÇÃO}

Em climas tropicais e subtropicais, os valores de temperatura e umidade relativa do ar são restritivos ao desenvolvimento, à produção e à reprodução dos animais (Oliveira et al., 1995). Este fato é comprovado sobretudo na avicultura, sendo que a habilidade apresentada pelas aves na troca térmica com o ambiente é fortemente afetada pelas instalações. Como os galpões avícolas brasileiros não são termicamente isolados, as amplitudes críticas de temperatura e umidade externas são imediatamente transferidas para o interior dos galpões, podendo provocar altos índices de mortalidade (Nacas et al., 1995).

Considerando-se que a temperatura interna das aves oscila entre $40-41^{\circ} \mathrm{C}$, a temperatura ambiente indicada para frango de corte, poedeiras e matrizes, segundo Ferreira (2005), poderá oscilar entre 15 e $28^{\circ} \mathrm{C}$, sendo que nos primeiros dias de vida a temperatura deve ficar entre 33 a $34^{\circ} \mathrm{C}$, dependendo da umidade relativa do ar, que pode variar de 40 a $80 \%$.

Do ponto de vista bioclimático, um dos principais fatores que influenciam na carga térmica de radiação incidente, são os telhados, principalmente em decorrência dos materiais de cobertura (Silva \& Sevegnani, 2001). Para Nããs et al. (2001) o telhado é o elemento construtivo mais significativo em uma instalação avícola, quanto ao controle da radiação solar incidente. Trindade (2006) encontrou em trabalhos na região semi-árida paraibana, analisando o conforto térmico em galpões cobertos com telha de cimento-amianto, com e sem nebulização interna, nos horários mais quentes do dia (entre 10 e $14 \mathrm{~h}$ ), valores de temperatura ambiente e ITGU acima da zona de conforto térmico, mas esses valores não interferiram nos índices produtivos.

Silva et al. (1990) estudando o efeito do ITGU em abrigos cobertos com telhas de cimento-amianto e telha cerâmica capa-canal, concluíram que a telha de cerâmica proporcionou valores menores de ITGU e de CTR que a telha de cimento amianto. Ferreira (2005) descreve que aves adultas apresentam melhor produção quando estão em ambientes com umidade relativa na faixa de 40 a $70 \%$. Segundo Donald (1998), em ambientes com $26,7^{\circ} \mathrm{C}$ e umidade relativa de $60 \%$, as aves completamente emplumadas estão próximas ao limite superior de sua zona de conforto, ou seja, não estão estressadas pelo calor, porém em ambientes com a mesma temperatura e umidade relativa do ar superior a $80 \%$, se tornam desconfortáveis e isto prejudica seu desempenho.

De acordo com Molina (1992) as linhagens de matrizes de corte são menos tolerantes ao calor que as linhagens de postura, havendo uma correlação negativa com o peso corporal; devido a esta correlação negativa, as matrizes pesadas são mais afetadas pelas temperaturas altas. Altas temperaturas, além de provocar redução no desempenho das aves, induzem a uma hiper-ventilação dos pulmões durante a respiração, com perda excessiva de dióxido de carbono do sangue, fator importante na formação do carbonato de cálcio para a casca.

Objetivou-se, com este trabalho, analisar os índices de conforto térmico de pintainhas de aves de postura, nas fases de cria e recria, sendo que na primeira fase se utilizou um galpão coberto com telha de cerâmica e, na segunda, dois galpões, sendo um coberto de telhas de cimento amianto e outro com cobertura de telhas cerâmica; a comparação foi realizada com base nas variáveis relacionadas ao conforto térmico ambiente: umidade relativa do ar (UR), índice de temperatura do globo negro e umidade (ITGU) e carga térmica de radiação (CTR).

\section{MATERIAL E MÉTODOS}

O experimento foi realizado em galpões de aves de postura, pertencentes à granja São Joaquim, localizados no município de Lagoa Seca, PB, com altitude de $634 \mathrm{~m}$, latitude de $07^{\circ} 10^{\prime} 15^{\prime}$ ' S e longitude de $35^{\circ} 51^{\prime} 13^{\prime}$ ' W. De acordo com a classificação climática de Koeppen, o clima da região é o tropical sub-úmido e temperatura média mensal de $25^{\circ} \mathrm{C}$.

O experimento foi conduzido em galpões de poedeiras nas fases de cria e recria, durante os meses de setembro de 2003 a fevereiro de 2004 e se utilizaram 2.240 pintainhas da linhagem “Lohmann Brown” (semi-pesadas). Foi utilizado um galpão para a fase de cria, com cobertura de telhas cerâmicas (GTC), comprimento de $30 \mathrm{~m}$, largura de $10,20 \mathrm{~m}$, altura do pé direito de $3,5 \mathrm{~m}$, mureta de $0,4 \mathrm{~m}$ de altura e piso concretado e dois galpões para a fase de recria, um dos quais coberto com telha de cimento amianto, com telha ondulada de 0,06 m de espessura caracterizado neste experimento como GTA e o outro galpão coberto com telha cerâmica comercial, caracterizado como GTC. Os galpões tinham largura de 8,3 m; comprimento de $19,3 \mathrm{~m}$, altura do pé direito de 2,10 m, beiral de $04 \mathrm{~m}$ de comprimento, presença de muretas de $0,20 \mathrm{~m}$ e o piso interno concretado.

Utilizaram-se, a partir da fase de cria, que compreendeu o período entre o $1^{\circ}$ dia de vida das pintainhas até o $60^{\circ}$ dia, 2.240 pintainhas, mantidas em círculos de proteção com capacidade para 500 pintainhas cada um, aquecidos com campânulas e sistema de luz 24 h, até a $4^{\text {a }}$. semana, diminuindo gradativamente as horas de luz, desligando-as nos horários mais quentes do dia (das 10 às $16 \mathrm{~h}$ ), voltando a ligá-las à noite, até a $8^{\mathrm{a}}$ semana. Os círculos foram abertos semanalmente com o intuito de se aumentar o espaço físico das aves; utilizaram-se comedouros tipo bandeja e bebedouros pendulares, a uma altura inicial de $5 \mathrm{~cm}$. A ração comercial para pintos foi usada, não havendo alterações no arraçoamento. A cama utilizada no piso do galpão foi maravalha de madeira com espessura de $10,0 \mathrm{~cm}$.

Após a $8^{\mathrm{a}}$ semana de vida, as pintainhas foram transferidas para baterias de gaiolas de recria em arame galvanizado, com bebedouros acopladas tipo nipple e comedouros do tipo calha; essas gaiolas não possuíam calha para o acolhimento de ovos, medindo 50 x 80 x $50 \mathrm{~cm}$, com capacidade para 6 aves cada uma.

Durante o período experimental as aves tiveram o mesmo manejo, receberam formulações de rações idênticas, de acordo com a sua fase de criação. A partir do seu $1^{\circ}$ dia de vida, coletou-se as temperaturas do globo negro, bulbo seco 
e úmido, velocidade do ar, na parte interna e externa dos galpões, cujas leituras foram realizadas a cada duas horas, das 8 às $16 \mathrm{~h}$.

As temperaturas de globo negro foram determinadas através de termômetro de globo negro, instalados nos galpões nas fases analisadas; na fase de cria, três termômetros foram colocados na altura de $0,20 \mathrm{~m}$, no centro do círculo de proteção das pintainhas e levantados semanalmente com a ampliação do círculo de proteção. Na fase de recria foram instalados à altura da cabeça das aves, enquanto as temperaturas de bulbo seco e bulbo úmido foram medidas através de psicrômetros instalados no pinteiro, um em cada círculo de proteção, na altura de $0,20 \mathrm{~m}$ do chão. Nas fases de recria e postura foram dispostos no início, meio e fim de cada galpão experimental, na altura de 1,0 m.

A velocidade do ar foi obtida instantaneamente, através de anemômetro digital de hélice, com resolução de $0,01 \mathrm{~m} \mathrm{~s}^{-1}$ e, no instante da leitura, o sensor estava posicionado no centro de cada galpão.

Os dados externos de temperatura de bulbo seco, bulbo úmido e velocidade do vento, foram coletados através de equipamentos localizados em um abrigo meteorológico; a temperatura do globo negro foi coletada próximo ao abrigo e exposto ao sol. O abrigo foi colocado próximo aos dois galpões, a uma altura de $1,5 \mathrm{~m}$, com a frente voltada para o sul. Para a análise dos índices térmicos nos diferentes ambientes, considerou-se o delineamento experimental inteiramente ao acaso, no esquema de parcelas subdivididas tendo-se, nas parcelas, os 2 tipos de material de cobertura (telha de amianto e cerâmica); nas subparcelas, os 5 tempos de observação (8, 10, 12, 14 e 16 h), com as repetições sendo os números de dias do experimento, e os resultados foram interpretados estatisticamente, segundo Silva (1996), e as médias foram comparadas pelo teste de Tukey, adotando-se o nível de 1 e 5\% de probabilidade, respectivamente.

\section{RESULTADOS E DISCUSSÃO}

\section{Diagnóstico das condições de conforto na fase de cria}

Verifica-se, na Tabela 1, que a UR obtida no interior do galpão de cria, não diferiu estatisticamente $(P>0,05)$, em função dos horários, enquanto no exterior ocorreu diminuição significativa da UR $(P>0,05)$ nos horários das 12 e $14 \mathrm{~h}$; no entanto, ao se comparar os dados internos e externos, constata-se diferença estatística entre 12 e 14 h, sendo que os menores valores de UR foram obtidos no ambiente externo. As médias de UR encontradas no interior do galpão em todos os horários, estiveram uniformes e dentro dos padrões indicados como confortáveis e adequados para a criação de poedeiras por Clark (1981), Yousef (1985) e Ferreira (2005).

Para minimizar a desidratação dos pintos, os níveis de UR nos primeiros dias devem ser de $70 \%$ e, após este período, de 50 a 60\%, aceitáveis. Os valores máximos e mínimos de UR encontradas no GTC não ultrapassaram os valores de 80 e $40 \%$, considerados extremos da zona de conforto para aves jovens (Ferreira, 2005). A manutenção da UR sem grandes oscilações é fundamental para o desenvolvimento das pintainhas e a uniformidade da UR obtida neste experimento, fato que se explica em virtude do interior das instalações ser protegido de correntes de ar, com lonas vinil, além da cobertura de telha cerâmica, que é bastante eficiente na manutenção da UR.

Tabela 1. Valores médios ${ }^{1}$ da umidade relativa (\%), índice de temperatura do globo negro e umidade e carga térmica de radiação $\left(\mathrm{w} \mathrm{m}^{-2}\right)$, para o galpão com cobertura de telha cerâmica (GTC) e para o exterior (EXT), na fase de cria

\begin{tabular}{cccccc}
\hline \multirow{5}{*}{ Sistemas } & $\mathbf{5}$ Horários \\
\cline { 2 - 6 } & $\mathbf{8}$ & $\mathbf{1 0}$ & $\mathbf{1 2}$ & $\mathbf{1 4}$ & $\mathbf{1 6}$ \\
GTC & $72,7 \mathrm{Aa}$ & $64,7 \mathrm{Aa}$ & $63,6 \mathrm{Aa}$ & $60,7 \mathrm{Aa}$ & $63,7 \mathrm{Aa}$ \\
EXT & $61,1 \mathrm{Aa}$ & $53,4 \mathrm{Aa}$ & $49,0 \mathrm{Bb}$ & $46,8 \mathrm{Bb}$ & $51,4 \mathrm{Ab}$ \\
\hline \multicolumn{7}{c}{ Índice de temperatura do globo negro e umidade } \\
\hline GTC & $75,1 \mathrm{Aa}$ & $77,0 \mathrm{Aa}$ & $78,8 \mathrm{Ab}$ & $79,2 \mathrm{Ab}$ & $77,4 \mathrm{Aa}$ \\
EXT & $82,0 \mathrm{Ab}$ & $85,3 \mathrm{Ab}$ & $87,6 \mathrm{Bb}$ & $90,4 \mathrm{Bb}$ & $85,2 \mathrm{Ab}$ \\
\hline \multicolumn{7}{c}{ Carga térmica de radiação } & $\left(\mathrm{w} \mathrm{m} \mathrm{m}^{-2}\right)$ \\
GTC & $457,3 \mathrm{Aa}$ & $468,4 \mathrm{Aa}$ & $477,5 \mathrm{Aa}$ & $478,8 \mathrm{Aa}$ & $468,7 \mathrm{Aa}$ \\
EXT & $519,5 \mathrm{Ab}$ & $543,9 \mathrm{Ab}$ & $656,2 \mathrm{Bb}$ & $587,0 \mathrm{Bb}$ & $544,3 \mathrm{Ab}$ \\
\hline
\end{tabular}

${ }^{1}$ Médias seguidas das mesmas letras, maiúsculas nas linhas e minúsculas nas colunas, não diferem entre si pelo teste de Tukey $(P<0,05)$

Analisando-se o ITGU nota-se, na Tabela 1, que tanto no galpão como no ambiente externo ocorreu aumento neste índice, das 8 às 14 h, e decréscimo às 16 h; contudo, esses valores não apresentaram diferenças significativas entre si a não ser no ambiente externo, no horário das 14 e 16 h, considerado um dos horários que causam maior dano às aves por estresse calórico. Os dados encontrados mostram que os valores do ITGU no galpão foram inferiores ao externo, em todos os horários pesquisados. Furtado et al. (2003), Sarmento et al. (2005) e Trindade (2006), encontraram em trabalhos com aves na região semi-árida nordestina, no ambiente interno, valores de ITGU crescentes até as $14 \mathrm{~h}$, decrescendo a partir deste horário, sendo que nos horários das 12 e 14 h, considerados os mais críticos do dia, ocorreu situação semelhante à encontrada nesta pesquisa; referidos valores divergem, em parte, dos encontrados por Teixeira (1983), que encontrou valores de conforto térmico ideal entre 78,5 e 81,6 para frangos de corte, nos horários das 12 e $14 \mathrm{~h}$, proporcionando maior conforto às pintainhas nas primeiras semanas.

Tomando-se por base os valores de Cella et al. (2001) que descrevem, para pintos de corte de 1 dia, 81,6 como nível de conforto térmico de ITGU e, para pintos com idade mais avançada, níveis de conforto na faixa de 72,9 de ITGU; observa-se, nas primeiras semanas de vida das pintainhas, falha no aquecimento, já que os valores médios encontrados em todos os horários foram inferiores aos sugeridos pelo autor e, nas últimas semanas, houve aquecimento do ambiente, que ficou acima do recomendado.

Verifica-se, na Tabela 1, um aumento nos valores da CTR no ambiente interno entre os horários estudados, das 8 às 14 h, apesar de não haver diferença estatística $(\mathrm{P}>0,05)$ para esses valores. Esta tendência também foi observada nos valores da CTR do ambiente exterior, havendo diferença 
significativa $(\mathrm{P}>0,05)$ nos horários das 12, 14 e 16 h; ao se compararem os valores da CTR entre o galpão e o ambiente externo, verifica-se que estes são menores para a GTC, em todos os horários e diferem entre si estatisticamente $(\mathrm{P}>0,05)$; pode-se observar, também, que tanto para o ambiente externo como para o interno ocorre elevação de CTR até as 14 h, voltando a decrescer a partir daí; e esta redução da CTR se dá em maior escala quando são utilizados artifícios como aspersão sobre a cobertura, pintura com cores claras na face superior da cobertura e sombreamento natural (Campos, 1986; Tinoco, 1998).

\section{Diagnóstico das condições de conforto na fase de recria}

Os valores médios da umidade relativa do ar, índice de temperatura do globo negro e umidade e carga térmica de radiação, para o galpão com cobertura de telha de cimento amianto (GTA), galpão com cobertura de telha cerâmica (GTC) e para o exterior (EXT), na fase de recria, estão apresentados na Tabela 2, na qual se verifica que entre o GTA, GTC e exterior, diferença estatisticamente significativa $(P>0,05)$ entre os horários analisados, com diminuição da UR às 8 e 14 h, aumentando no final da tarde; não se constatou, porem diferença estatística entre os tratamentos com telha de barro e de cimento amianto. Furtado et al. (2003), em trabalhos com frangos de corte na mesma região onde foi realizada a presente pesquisa, em galpões com telha de cerâmica e amianto, encontraram valores de UR inferiores aos descritos, nos horários das 10, 12 e 14 h.

Considerando-se a faixa ideal de valores de UR entre 50 e 70\% (Ferreira, 2005), observa-se que GTA e GTC conseguiram manter níveis ideais de umidade para produção não ultrapassando, em nenhum horário, os limites de 40 e $80 \%$. Moura (2001) cita que aves com cinco meses de idade e com níveis adequados de umidade relativa (menores que $75 \%$ ), suportam temperaturas acima de $27^{\circ} \mathrm{C}$ sem problemas, estando em concordância com os resultados obtidos no presente trabalho.

Tabela 2. Valores médios da umidade relativa do ar (\%), índice de temperatura do globo negro e umidade e carga térmica de radiação (w m $\left.{ }^{-2}\right)$, para o galpão com cobertura de telha cerâmica (GTC), galpão com cobertura de telha de cimento amianto (GTA) e para o exterior (EXT), na fase de recria

\begin{tabular}{cccccc}
\hline \multirow{5}{*}{ Sistema } & \multicolumn{5}{c}{ Horários } \\
\cline { 2 - 6 } & $\mathbf{8}$ & $\mathbf{5}$ & $\mathbf{1 2}$ & $\mathbf{1 4}$ & $\mathbf{1 6}$ \\
GTC & $75,5 \mathrm{Aa}$ & $67,8 \mathrm{Ba}$ & $63,5 \mathrm{Ca}$ & $65,3 \mathrm{Da}$ & $63,7 \mathrm{Aa}$ \\
GTA & $73,6 \mathrm{Aa}$ & $67,7 \mathrm{Ba}$ & $64,4 \mathrm{Ba}$ & $58,6 \mathrm{Da}$ & $66,0 \mathrm{Ca}$ \\
\hline EXT & $75,7 \mathrm{Aa}$ & $70,5 \mathrm{Ba}$ & $67,4 \mathrm{BCa}$ & $\mathbf{4} 6.8 \mathrm{Bb}$ & $69,3 \mathrm{Ab}$ \\
\multicolumn{5}{c}{ Índice de temperatura do globo negro e umidade } \\
GTC & $72,3 \mathrm{Aa}$ & $73,9 \mathrm{Aa}$ & $75,8 \mathrm{ABa}$ & $77,1 \mathrm{Ba}$ & $78,3 \mathrm{Ba}$ \\
GTA & $73,8 \mathrm{Aa}$ & $75,7 \mathrm{Aa}$ & $76,7 \mathrm{ABa}$ & $78,5 \mathrm{Ba}$ & $77,6 \mathrm{BCa}$ \\
EXT & $77,5 \mathrm{Ab}$ & $80,3 \mathrm{Bb}$ & $82,6 \mathrm{Bb}$ & $84,8 \mathrm{Cb}$ & $81,8 \mathrm{Bb}$ \\
\hline \multicolumn{5}{c}{ Carga térmica de radiação } & $(\mathrm{w} \mathrm{m}-2)$ \\
GTC & $442,2 \mathrm{Ba}$ & $450,6 \mathrm{Ba}$ & $462,8 \mathrm{ABa}$ & $469,4 \mathrm{ABa}$ & $481,5 \mathrm{Aa}$ \\
GTA & $448,7 \mathrm{Ba}$ & $460,1 \mathrm{Ba}$ & $489,9 \mathrm{Ab}$ & $485,5 \mathrm{Ab}$ & $470,7 \mathrm{ABa}$ \\
EXT & $483,3 \mathrm{Ab}$ & $503,1 \mathrm{Ab}$ & $520,6 \mathrm{Ac}$ & $537,1 \mathrm{Ac}$ & $515,6 \mathrm{Ab}$ \\
\hline
\end{tabular}

Médias seguidas das mesmas letras, maiúsculas nas linhas e minúsculas nas colunas, não diferem entre si pelo teste de Tukey $(P<0,05)$
Analisando-se o ITGU, observa-se no GTA, diferença estatisticamente significativa $(\mathrm{P}>0,05)$ entre os horários analisados, com aumento do ITGU das 08 às $12 \mathrm{~h}$, voltando depois a diminuir; para o tratamento GTC, verificou-se um aumento estatisticamente significativo $(\mathrm{P}>0,05)$ do ITGU, em relação às 8 e às $16 \mathrm{~h}$. Observando-se os dados da tabela, nos horários das 8, 14 e 16 h, nota-se que não houve diferença estatística entre os sistemas de acondicionamento e o exterior, enquanto no horário das 10 h o GTC foi estatisticamente diferente em relação ao exterior, não havendo porém, diferença entre este sistema e o GTA, ao contrário do horário das 12 h, quando estes foram estatisticamente diferentes.

Tomando-se por base os valores citados por Tinoco (1998), em que o ITGU de até 75 é considerado como de conforto térmico para poedeiras, tem-se que no GTA, no horário das 10, 12, 14 e 16 h, o ITGU ficou acima do recomendado, principalmente no horário das 12 h que, segundo Baeta \& Souza (1997), caracteriza uma situação de perigo; no GTC, esta elevação ocorreu no horário das 12, 14 e 16 h, caracterizando uma situação de desconforto térmico. Comparando-se o GTA e o GTC, constata-se maior eficiência do GTC que propiciou, no horário de maior desconforto térmico (12 h), valores de ITGU menores que o GTA. Dados semelhantes de ITGU foram relatados por Tinoco (2001) com matrizes pesadas em sistema natural.

Com relação à CTR observa-se, na Tabela 2, que o GTA, quanto aos horários, apresentou diferença significativa ( $\mathrm{P}>0,05)$ apenas no horário das $12 \mathrm{~h}$, que registrou os maiores índices. Para o tratamento GTC, notou-se aumento estatisticamente significativo $(\mathrm{P}>0,05)$ da CTR em relação às 8 e às 16 h, enquanto no ambiente externo não se verificaram diferenças estatisticamente significativas $(P>0,05)$ nos variados horários. Em relação às médias de CTR e em função dos tratamentos utilizados, observa-se que os tratamentos GTA e externo não apresentaram diferença estatística e, também, que o tratamento GTC apresentou médias de CTR estatisticamente menores, em relação aos outros tratamentos, às 8 e às $12 \mathrm{~h}$, e a partir das $14 \mathrm{~h}$ se apresentaram estatisticamente semelhantes.

Trabalho realizado por Furtado et al. (2003), com frangos de corte, na mesma região onde foi realizada a presente pesquisa, em galpões com telha de cerâmica e amianto, relatam valores de CTR superiores aos tratamentos GTA e GTC, em todos os horários analisados. Trindade (2006), em pesquisa com poedeiras na região semi-árida nordestina, relata valores de CTR, nos horários das 8 e 10 h, semelhantes ao encontrado no tratamento GTC, e superior no horário das 12 h.

\section{CONCLUSÕES}

1. Durante a etapa inicial da fase de cria, ocorreu falha no aquecimento das pintainhas, já que índices ambientais ficaram abaixo do desejado e, na fase final, o ambiente proporcionou índices ambientais elevados.

2. Na fase de recria o galpão com cobertura de telhas cerâmicas apresentou, nos horários mais quentes do dia, melhor 
resultado na carga térmica de radiação, em comparação com o galpão com cobertura de telha de cimento amianto, proporcionando melhor conforto térmico para poedeiras.

\section{LITERATURA CITADA}

Baêta, F. C.; Souza, C. F. Ambiência em edificações rurais - conforto animal. Viçosa: UFV, 1997, 246p.

Campos, A. T. Determinação dos índices de conforto térmico e da carga térmica de radiação em quatro tipos de galpões em condições de verão para Viçosa, MG. Viçosa: UFV, 1986, 66p. Dissertação Mestrado

Cella, P. S.; Donzele, J. L.; Oliveira, R. M.; Albino, L. F. T.; Ferreira, A. S. Níveis de lisina mantendo a relação aminoacídica para frangos de corte no período de 1 a 21 dias de idade, em diferentes ambientes térmicos. Revista Brasileira de Zootecnia, Viçosa, v.30, n.2, p.440- 448, 2001

Clark, J. A. Enviromental aspects of housing for animal production. Northinghan: Brish University of Northinghan, Page Bros Ltd, 1981. 510p.

Donald, J. Environmental control options under different climatic conditions. World Poultry- Elsevier, v.14, n.11, p.2223, 1998.

Ferreira, R. A. Maior produção com melhor ambiente para aves, suínos e bovinos. Viçosa: Aprenda Fácil, 2005. 371p.

Furtado, D. A.; Azevedo, P. V.; Tinôco, I. F. F. Análise do conforto térmico em galpões avícolas com diferentes sistemas de acondicionamento. Revista Brasileira de Engenharia Agrícola e Ambiental, Campina Grande, v.7, n.3, p.559-564, 2003.

Molina, J. Manejando reproductoras en climas tropicales. Indústria Avícola, Venezuela, v.39, n.3, p.15-17, 1992.

Moura, D. J. Ambiência na avicultura de corte. In: Silva, I. J. O. Ambiência na produção de aves em clima tropical. Piracicaba: FUNEP, 2001. p.75-149.

Nããs, I. A.; Sevegnani, K. B.; Marcheto, F. G.; Espelho, J. C. C.; Menegassi, V.; Silva, I. J. O. Avaliação térmica de telhas de composição de celulose e betumem, pintadas de branco, em modelos de aviários com escala reduzida. Engenharia Agrícola, Jaboticabal, v.21, n.2, p.121-126, 2001.
Nacas, I. A.; Moura, D. J.; Laganá, C. A. A amplitude térmica e seu reflexo na produtividade de frangos de corte. In: Conferência Apinco de Ciência e Tecnologias Avícolas, 1995. Anais... Campinas: FACTA. 1995, p.203-204.

Oliveira, P. A. V.; Guidone, A. L.; Baroni Júnior, W.; Dalmoura, V. J.; Castanha, N. Efeito do tipo de telha sobre o acondicionamento ambiental e o desempenho de frangos de corte. In: Conferência Apinco de Ciência e Tecnologia Avicolas, 1995, Curitiba. Anais... Curitiba: FACTA, 1995. p.297-298.

Sarmento, L. G. V.; Dantas, R. T. D.; Furtado, D. A.; Nascimento, J. W. B.; Silva, J. H. V. Efeito da pintura externa do telhado sobre o ambiente climático e o desempenho de frangos de corte. Revista Agropecuária Técnica, Areia, v.26, n.2, p.152-159, 2005.

Silva, F. A. S. The assistat software: statistical assistance. In: International Conference on Computers in Agriculture, 6, Cancun, 1996. Anais... Cancun: American Society of Agricultural Engineers, 1996. p.294-298.

Silva, I. J. O.; Guelfi Filho, H.; Consigliero. F. R. Influência dos materiais de cobertura no conforto térmico de abrigos. Engenharia Rural, Piracicaba, v.1, n.2, p. 43-55, 1990.

Silva, I. J. O.; Sevegnani, K. B. Ambiência na produção de aves de postura. In: Silva, I. J. O. Ambiência na produção de aves em clima tropical. Piracicaba: FUNEP, p.150- 214, 2001.

Teixeira, V. H. Estudo dos índices de conforto em duas instalações de frango de corte para a região de Viçosa e Visconde do Rio Branco, M.G. Viçosa: UFV, 1983. 62p. Dissertação Mestrado

Tinôco, I. F. F. Ambiência e instalações para a avicultura industrial. In: Congresso Brasileiro de Engenharia Agrícola, 27, e Encontro Nacional de Técnicos, Pesquisadores e Educadores de Construções Rurais, 3, 1998, Poços de Caldas. Anais... Lavras: UFLA/SBEA, 1998, p.1-86.

Tinôco, I. F. F. Ambiência e instalações na produção de matrizes avícolas. Silva. I. J. O., Ambiência na produção de aves em clima tropical. Piracicaba: FUNEP, p.17- 27, 2001.

Trindade, J. L. Diagnóstico ambiental e índices zootécnicos em galpões de poedeiras no semi-árido paraibano. Campina Grande, UFCG, 2006, 68p. Dissertação Mestrado

Yousef, M. K. Stress physiology in livestock. V.III. Poultry. Las Vegas: CRC Press, Inc., 1985. 159p. 